\title{
GMR
}

Thesis Abstract

\section{Study of biochemical changes in blood and various organs of Phrynops geoffroanus (Schweigger, 1812) (Testudines: Chelidae) collected in contaminated environment or exposed to benzo[a]pyrene}

\author{
M.I.A. Silva, T.L. Silva and E.A. Almeida \\ 2015. Universidade Estadual Paulista, "Júlio de Mesquita Filho", \\ São José do Rio Preto, SP, Brasil \\ Doctoral thesis, Orienting Prof.: E.A. Almeida \\ Corresponding author: M.I.A. Silva \\ E-mail: bebel_afonso@yahoo.com.br \\ Genet. Mol. Res. 15 (1): gmr.15018568 \\ Received February 18, 2016 \\ Accepted February 18, 2016 \\ Published February 19, 2016 \\ DOI hattp://dx.doi.org/10.4238/gmr.15018568
}

The aquatic organisms are often exposed to a wide variety of chemicals, whose individual components are likely to produce different responses within the organisms and/or interact producing additive, synergistic or antagonistic toxic effects. Most of these substances are potentially cytotoxic, genotoxic or carcinogenic, such as polycyclic aromatic hydrocarbons (PAHs). The Phrynops geoffroanus species ("Geoffroy's side-necked turtle", Schweigger, 1812) is widely distributed in tropical and temperate areas of South America. This species is commonly found in impacted areas, and polluted rivers that cross the urban area and receive domestic and industrial wastewater effluents. In these environments, freshwater turtles are exposed to ecological pressures that threaten their conservation and can influence the animal life habits and physiological conditions. The objective of this study was to evaluate the biochemical changes in various organs (liver, heart, lung, pancreas, brain, small and large intestines) of $P$. geoffroanus from contaminated environment by human activities (sewage and industrial wastewater effluents) 
(Step 1) or exposed to benzo[a]pyrene, a PAHs model compound, for 7 days (Step 2). For this, we analyzed the responses of systems related to phases I and II of xenobiotics biotransformation, main antioxidant enzyme activities and malondialdehyde (MDA) levels, indicative of oxidative stress, as biomarkers for biomonitoring of pollutants impact. Furthermore, we have assessed the gamma glutamyl transferase enzymatic activity and DNA fragmentation by comet assay, in $P$. geoffroanus blood exposed to benzo[a]pyrene, in order to identify hepatic changes and genotoxicity according to the tested doses of this compound. The first step of this study analysis revealed an important influence of contamination by domestic and industrial wastewater effluents in free-living freshwater turtles that presented a series of changes in biomarkers analyzed. We observed higher MDA levels in animal organs from Felicidade stream when compared to those from the reference site (breeding farm - control group), indicating damage caused by reactive oxygen species due to the prooxidant contaminant presence. Due to environmental impact in the urban area, animals responded with an increase in their ability to detoxify chemicals compounds, exhibiting higher values of 7-ethoxyresorufin-O-deethylase (EROD), 7-benzyloxyresorufin-O-debenzylase (BROD), 7-pentoxyresorufin-O-depentylase (PROD), glutathione S-transferase, glutathione peroxidase, and catalase activities and reduced glutathione concentration in several organs, as enzymatic adjustment in order to avoid damage caused by local stressors. In both steps of this study, our results showed alterations of several biomarkers in specific organs, indicating differences in susceptibility among different organs of this species. Concerning the three doses of benzo[a]pyrene tried in the second step, this freshwater turtle species demonstrated exposure resistance and effective defense mechanisms against contamination, since there was not increase in MDA levels of the organs. In addition, EROD, BROD, and PROD were also responsive to benzo[a]pyrene exposure, suggesting the role of these enzymes in the metabolism of this compound. In most analyses, the lowest dose of benzo[a]pyrene $(100 \mu \mathrm{g} / \mathrm{kg})$, in an exposure period of seven days, had no effect on the enzyme activities in the organs evaluated. Most of the alterations observed was increased enzyme activity in groups submitted to the two highest doses, 500 and $1000 \mu \mathrm{g} / \mathrm{kg}$, as a defense response to chemical stressors, involving detoxification of reactive intermediates. The analysis of GGT activity and comet assay demonstrated a significant and dose-dependent increase in the groups treated with benzo[a]pyrene doses of 500 and $1000 \mu \mathrm{g} / \mathrm{kg}$, compared to the control group, indicating an association between exposure to contaminant and an increase in hepatic and blood cell DNA damages. These data are very important for the knowledge of the chelonian physiology, also contributing to the design of improved strategies for the group conservation.

Keywords: Ecotoxicology; biomarkers; environmental changes; benzo[a]pyrene; Phrynops geoffroanus

\title{
ACKNOWLEDGMENTS
}

\author{
Research supported by FAPESP (Process \#2011/06680-8).
}

